\title{
Smoking among school-going adolescents in selected secondary schools in Peninsular Malaysia- findings from the Malaysian Adolescent Health Risk Behaviour (MyaHRB) study
}

Kuang Hock Lim", Hui Li Lim², Chien Huey Teh', Chee Cheong Kee ${ }^{1}$, Yi Yi Khoo ${ }^{3}$, Shubash Shander Ganapathy ${ }^{3}$, Miaw Yn Jane Ling ${ }^{3}$, Sumarni Mohd Ghazali ${ }^{1}$ and Eng Ong Tee ${ }^{4}$

\begin{abstract}
Background: A multitude of studies have revealed that smoking is a learned behaviour during adolescence and efforts to reduce the incidence of smoking has been identified as long-term measures to curb the smoking menace. The objective of this study was to determine the prevalence as well as the intra and inter-personal factors associated with smoking among upper secondary school students in selected schools in Peninsular Malaysia.

Methods: A study was carried out in 2013, which involved a total of 40 secondary schools. They were randomly selected using a two-stage clustering sampling method. Subsequently, all upper secondary school students (aged 16 to 17 years) from each selected school were recruited into the study. Data was collected using a validated standardised questionnaire.

Results: This study revealed that the prevalence of smoking was 14.6\% (95\% Cl:13.3-15.9), and it was significantly higher among males compared to females $(27.9 \%$ vs $2.4 \%, p<0.001)$. Majority of smokers initiated smoking during their early adolescent years (60\%) and almost half of the respondents bought cigarettes themselves from the store. Multivariable analysis revealed that the following factors increased the likelihood of being a current smoker: being male (aOR 21. 51,95\% Cl:13.1-35), perceived poor academic achievement (aOR 3.42, 95\% Cl:1.50-7.37) had one or both parents who smoked (aOR 1.80, 95\% Cl:1.32-2.45; aOR 6.50, 95 Cl\%:1.65-25.65), and always feeling lonely (aOR 2.23, 95\% Cl:1.21-4.43). In contrast, respondents with a higher religiosity score and protection score were less likely to smoke (aOR 0.51, 95\% Cl:0.15-0.92; aOR 0.71, 95\% Cl 0.55-0.92).

Conclusion: This study demonstrated that the prevalence of smoking among Malaysian adolescents of schoolgoing age was high, despite implementation of several anti-smoking measures in Malaysia. More robust measures integrating the factors identified in this study are strongly recommended to curb the smoking epidemic among adolescents in Malaysia.
\end{abstract}

Keywords: Adolescent smoking, Intrapersonal, Interpersonal, School-going adolescents, Peninsular Malaysia

* Correspondence: limkh@imr.gov.my

'Institute for Medical Research, Jalan Pahang, 50588 Kuala Lumpur, Malaysia

Full list of author information is available at the end of the article 


\section{Background}

Mortality and morbidity due to smoking-related diseases are important public health issue globally [1]. The World Health Organization (WHO) reported that mortality due to smoking-related diseases was higher than the combination of all infectious diseases worldwide. By 2030, if there is no change in the trend, the mortality rate due to smoking will have increased by 2.5 fold, whereby $70 \%$ of this rate will be from developing and under-developed countries. In Malaysia, approximately 10,000 deaths attributed to smoking were reported annually [2], with 5.6 million years of life lost (YLLs) [3] and almost three billion Malaysian Ringgit (RM) had been spent to treat three smokingrelated diseases, namely chronic obstructive pulmonary disease (COPD), ischemic heart disease (IHD) and lung cancer [4]. In addition, studies had also demonstrated that smokers were more likely to indulge in high-risk health behaviours such as use of illicit drugs [5], pre-marital sex [6] and alcohol usage [7].

A plethora of studies have shown that majority of adult smokers initiated smoking during their adolescent years $[8,9]$, and they were more inclined to continue this habit into their adulthood [9] and more likely to be afflicted by smoking-related diseases and less likely to cease smoking [10]. In order to prevent smoking initiation at young age, determination of correlates of adolescent smoking is of paramount importance for anti-smoking policy planning and implementation.

Studies have shown that smoking is a complex behaviour. Some of the identified contributory factors to adolescent smoking include intra- and inter-personal factors and environmental factors [11-18]. Although research on smoking among adolescents in Malaysia had been carried out over the past few decades, these studies, including the nationwide studies were mainly concentrated on prevalence and psychosocial factors [11, 12, 15-17]. Intrapersonal factors such as unsatisfactory academic achievement and religiosity were not given due attention. Therefore, this manuscript aimed to address the knowledge gaps by determining the prevalence of smoking, characteristics of smokers, as well as inter and intra-personal factor(s) associated with smoking among upper secondary school adolescents (aged 16 to 17 years old) in selected schools in Peninsular Malaysia. These findings could provide evidence-based findings to enable the formulation and implementation of suitable policies to curb the increasing burden of smoking-related morbidity and mortality in Malaysia, especially amongst the smoking adolescents aged 16 to 17 years.

\section{Methods}

The MyAHRB study was a cross-sectional study conducted in 11 states involving 20 districts in Peninsular Malaysia from May to September 2013. Two-stage proportionate-to-size sampling technique was utilised to obtain the sample of schools; the first stage involved the selection of districts with Clinical Training Centres (CTCs) for public health paramedics, followed by stratification of schools by locality (urban/rural). Two secondary schools were then randomly selected from each district via simple random sampling method. As a result, a total of 40 schools were selected (20 schools in urban and 20 in rural area). All students aged 16-17 years from the selected schools were recruited as participants. Students of non-Malaysian citizenship were excluded from the study. The sample size was determined using an estimated prevalence of suicidal ideation from pretest (3\%), a design effect of 3 to cater for clustering effect from each school, a precision of $1.5 \%$ and a nonresponse rate of $20 \%$. Based on this parameters, a total of 3578 respondents were needed for the study.

\section{Study instrument}

A validated self-administered questionnaires was used in the MyAHRB study. The structured questionnaire consisted of four sections: sociodemography (age, gender and ethnicity), self-perceived academic achievement, parent/s' educational level, parent/s' occupation, household size, parents' marital status (married/divorced), health-risk behaviour [alcohol consumption, sexual behaviour], Rosenberg Self-Esteem Scale and religiosity.

Health-risk behaviours were assessed using a questionnaire adapted from the Global School-based Student's Health Survey (GSHS) [19] and the Youth Risk Behaviour Surveillance (YBRS) [20]. The health-risk behaviour items were translated by a panel of experts consisting of language and content experts, using backward and forward translation processes. The Rosenberg Self-Esteem Scale was adopted from Jamil [21] whereas the religiosity items were adopted from a health behaviour study questionnaire developed by University Putra Malaysia. The questionnaire was pre-tested and further modified based on feedback from selected students in certain schools in Kuala Lumpur to suit the local socio-cultural context.

The permission to conduct the MyaHRB study was granted by the Ministry of Education and State Education Department. Ethical approval was obtained from the Malaysia Research Ethics Committee, Ministry of Health Malaysia.

\section{Measures}

Consent was obtained from parents/guardians of the selected students. The consent form provided information about the participation of their children in the study, as well as the study objectives. Participations of students were of voluntary basis and parents/guardians of the selected respondents were asked to return the consent form if they did not agree for their son/daughter to participate 
in the study. Only respondents who did not return the consent form were allowed to participate in the study. Data collection was carried out in the designated area allocated by the school administration. Staff and teachers were not allowed to be around during the questionnaireanswering session to avoid "Hawthorne effect". Briefing was given by the team members before the session began. This included the objectives of the study, the anonymity of the answers given, awareness that their participation was on a voluntarily basis, as well as an explanation of the items in the questionnaire. Respondents were also requested not to write their names or provide any information that would reveal their identities, with the exception of their signatures which indicated their willingness to participate in the study. Respondents who did not understand certain items in the questionnaire were assisted by the research team members. All completed questionnaires were sealed in envelopes.

The dependent variable in this questionnaire was "current smoker", which was evaluated using the item "In the last 30 days, how often did you smoke?". Respondents who answered "every day", "almost every day", "2-3 times a week", "once a week" and "once a month" were classified as "current smoker" whilst those who answered "I did not smoke" during the last 30 days were categorized as "nonsmoker". Those who answered "smoked at least once a month" were required to answer their age of smoking initiation, quantity of cigarettes smoked per day and source of cigarettes. Those who smoked less than 11 sticks per day was classified as light smoker, 11-20 sticks as moderate smoker and more than 20 sticks per day as heavy smoker. The independent variables included "parents/ guardian who smoked", "perception of academic achievement ", family status (whether their parents were married/ divorced), and education attainment of their parents. A validated Malay version of the Rosenberg Self-Esteem Scale was used to evaluate the level of self-esteem, whereby those who scored less than 15 were categorized as having "low self-esteem" and 15-30 as having "high self-esteem". The protection factor was evaluated using 6 items (for example "My parents know what I am doing during my free time", "friends always help me in school"). Religiosity was examined using three items (for example "Do you agree that religion is very important to guide your life?"). Both these variables were measured using the Likert-type scale. A higher score indicated a higher protective factor in school and within their families as well as portrayed the importance of religion in daily life, respectively. The number of close friend(s) was measured using the item "How many close best friends do you have?" with the option "None, One, Two". Questions on how often they felt lonely was evaluated using the item "In the last one month how often do you feel lonely?" with the choice of "Always or sometimes".

\section{Data analysis}

The data were cleaned before the analysis, whereby outlier values were detected using frequency analysis and references were made against the original questionnaire if the investigators had any doubt about the answers given. Descriptive statistics was used to illustrate the demographic status of the respondents, age of smoking initiation, number of cigarettes smoked and source of cigarettes. Chi-square analysis was used to determine the association between smoking status and social demographic variables whilst independent $T$-test was used to determine the mean differences of protection and religiosity scores between smokers and nonsmokers. All independent variables with $p<0.25$ in univariate analysis (Chi-square and $T$-test) were included in the Multivariable Logistic Regression model to determine the effect of each independent variable after controlling the influence of other independent variables. A co-linearity test between religiosity and protection score was carried out by variant inflation factor and the value of 1.025 indicated no co-linearity between the two variables. A Hosmer-Lemeshow value of 0.25 indicated the fitness of the model. All possible two-way interactions between the independent variables in the final model were also analysed. No interaction with $p<0.05$ were detected, indicating no significant two-way interactions. All statistical analyses were run at $95 \%$ confidence interval using SPSS software version 16.

\section{Results}

A total of 2991 respondents participated in this study which led to an overall response rate of $83.6 \%$. Out of 2991 participants, 2794 of them responded to the question on smoking module, giving a response rate of $93.4 \%$ to this section. The students were composed almost equally by gender [51.8\% (1448/2794) were females and $48.2 \%$ (1346/2794) were males). The largest ethnic group likening to more than three-quarters of the respondents was Malays, followed by Chinese (14.8\%). The prevalence of smoking was $14.6 \%$ (408/2793) (95\% CI:13.3-15.9) and this was higher among male students as compared to females $(27.9 \%$ vs $2.4 \% p<0.001)$. Smoking prevalence was also significantly higher among the Malays, those who perceived their academic achievement as poor, who always felt lonely, had parent/s or guardian/s who smoked and with two best friends (Table 1).

Table 2 highlighted that almost $70 \%$ of current smokers bought cigarettes from the premises (i.e., sundry shops) by themselves and more than one-third of them smoked daily. Approximately 90\% of current smokers were light smokers (smoked less than 11 sticks per day) and almost two-thirds of them started smoking during upper primary or lower secondary school (aged 11-14 year old). Table 3 showed that respondents with 
Table 1 Prevalence of smoking among upper secondary school students in Peninsular Malaysia

\begin{tabular}{|c|c|c|c|c|}
\hline \multirow[t]{3}{*}{ Variable } & \multicolumn{2}{|l|}{ Smoking } & \multirow[t]{3}{*}{ Chi-square value } & \multirow[t]{3}{*}{$p$ value } \\
\hline & Yes & No & & \\
\hline & $N(\%)$ & $N(\%)$ & & \\
\hline \multicolumn{5}{|l|}{ Gender } \\
\hline Male & $373(27.9)$ & $963(72.1)$ & 361.3 & $<0.001$ \\
\hline Female & $35(2.4)$ & 1413(97.6) & & \\
\hline \multicolumn{5}{|l|}{ Ethnicity } \\
\hline Malay & $372(17.2)$ & 1812(82.8) & 59.2 & $<0.001$ \\
\hline Chinese & $18(4.6)$ & $375(95.4)$ & & \\
\hline Indian & $10(5.1)$ & 186(94.9) & & \\
\hline Others & $3(27.3)$ & $8(72.7)$ & & \\
\hline \multicolumn{5}{|c|}{ Academic Achievement } \\
\hline Excellence & 194(11.3) & 1516(88.7) & 51.7 & $<0.001$ \\
\hline Moderate & 181(18.9) & 779(81.1) & & \\
\hline Unsatisfactory & $32(32.4)$ & $70(68.6)$ & & \\
\hline \multicolumn{5}{|c|}{ Marital status of parents } \\
\hline Married & $380(14.5)$ & 2233(85.5) & 0.01 & 0.79 \\
\hline Divorced & 23(15.3) & 127(84.7) & & \\
\hline \multicolumn{5}{|c|}{ Level of self esteem } \\
\hline High & 192(16.3) & 988(83.7) & 6.37 & 0.012 \\
\hline Low & 189(12.8) & $1288(87.2)$ & & \\
\hline \multicolumn{5}{|l|}{ Loneliness } \\
\hline Always & $37(21.3)$ & 137(78.7) & 6.52 & 0.01 \\
\hline Sometimes & $370(14.2)$ & 2236(85.8) & & \\
\hline \multicolumn{5}{|c|}{ Number of parents Smoked } \\
\hline None & 209(11.1) & 1670(88.9) & 40.69 & $<0.001$ \\
\hline One & 145(18.8) & $627(81.2)$ & & \\
\hline Both & $8(42.1)$ & 11(57.9) & & \\
\hline \multicolumn{5}{|c|}{ Number of Best friend/s } \\
\hline None & $10(9.3)$ & 97(90.3) & 2.56 & 0.27 \\
\hline One & $14(13.2)$ & $91(86.8)$ & & \\
\hline Two & $380(14.8)$ & 218(85.2) & & \\
\hline
\end{tabular}

high protection and religiosity scores were less likely to smoke in the last 30 days (protection score 3.61 vs 3.42, $p<0.001$; religiosity score 3.67 vs $3.49, p<0.001$ ).

Multivariable analysis revealed that the odds of smoking increased among males (aOR 21.51, 95\% CI:13.1-35.1), those who perceived poor academic achievement (aOR 3.42, 95\% CI:1.50-7.37, excellent group as reference group), had both parents who smoked (aOR1.80, 95\% CI:1.32-2.45), had one parent who smoked, (aOR 6.50, 95\% CI:1.65-25.65, no parent smoked as reference), had two best friends (aOR 4.40, 95\% CI:1.38-14.03, having no best friend as reference) and always felt lonely (aOR 2.23, 95\% CI:1.21-4.43). On the other hand, respondents with higher religiosity score and protection score were less
Table 2 Smoking initiation age, number, frequency of smoking and source of cigarettes/s among current adolescent smoking

\begin{tabular}{|c|c|c|}
\hline Variable & $\mathrm{n}$ & $\%$ \\
\hline \multicolumn{3}{|c|}{ Smoking initiation Age (year) } \\
\hline Less than 7 & 14 & 3.5 \\
\hline $8-9$ & 23 & 5.7 \\
\hline $10-11$ & 60 & 14.9 \\
\hline $12-13$ & 125 & 31.1 \\
\hline $14-15$ & 148 & 36.8 \\
\hline 16 years & 34 & 8.5 \\
\hline \multicolumn{3}{|c|}{ Quantity of cigarettes daily } \\
\hline Less than 1 & 32 & 7.8 \\
\hline 1 & 72 & 17.6 \\
\hline $2-5$ & 179 & 43.8 \\
\hline $6-10$ & 53 & 13.0 \\
\hline $11-20$ & 22 & 5.4 \\
\hline$>20$ & 30 & 7.3 \\
\hline \multicolumn{3}{|c|}{ Frequency of smoking in the last 30 days } \\
\hline Daily & 143 & 34.7 \\
\hline $20-29$ & 37 & 9.0 \\
\hline $10-19$ & 40 & 9.7 \\
\hline $6-9$ & $41^{\prime}$ & 10 \\
\hline $3-5$ & 45 & 10.9 \\
\hline $1-2$ & 106 & 25.7 \\
\hline \multicolumn{3}{|l|}{ Source of cigarettes } \\
\hline Bought from shop & 253 & 69.9 \\
\hline Asked others to buy & 29 & 8.0 \\
\hline Bought from others & 45 & 12.4 \\
\hline Family member & 12 & 3.3 \\
\hline Others & 23 & 6.4 \\
\hline
\end{tabular}

likely to smoke (aOR 0.51, 95\% CI:0.15-0.92; aOR 0.71, 95\% CI:0.55-0.92) (Table 4).

\section{Discussion}

The prevalence of current smokers was $14.6 \%$, which was consistent to the $14.3 \%$ reported by $\mathrm{Lim} \mathrm{KH}$ et al. among adolescents in Petaling District [12]. However, this was almost 3\% higher than those reported in a nationwide study conducted in 2012 among secondary school students [11]

Table 3 Mean score for protection and Religiosity between smoking and non-smoking adolescents

\begin{tabular}{|c|c|c|c|c|}
\hline \multirow[t]{3}{*}{ Variable } & \multicolumn{4}{|l|}{ Smoking } \\
\hline & Yes & No & T score & $p$ value \\
\hline & Mean (sd) & Mean (sd) & & \\
\hline Protection scale & $3.42(0.51)$ & $3.61(0.59)$ & 5.40 & 0.001 \\
\hline Religiosity & $3.49(0.52)$ & $3.67(0.49)$ & 5.76 & 0.001 \\
\hline
\end{tabular}


Table 4 Factors related to smoking among adolescents using Multivariable Logistic Regression analysis

\begin{tabular}{|c|c|c|c|}
\hline Variable & Wald Value & Adjusted OR & $95 \mathrm{Cl}$ \\
\hline \multicolumn{4}{|l|}{ Gender } \\
\hline Male & 150.28 & 21.51 & $13.1-35.1$ \\
\hline Female & & 1 & \\
\hline \multicolumn{4}{|l|}{ Ethnicity } \\
\hline Malay & & 1 & \\
\hline Chinese & 28.54 & 0.09 & $0.04-0.22$ \\
\hline Indian & 15.16 & 0.18 & $0.07-0.40$ \\
\hline Others & 0.37 & 2.22 & $0.17-27.82$ \\
\hline \multicolumn{4}{|l|}{ Academic Achievement } \\
\hline Excellence & & 1 & \\
\hline Moderate & 3.42 & 1.34 & $0.98-1.82$ \\
\hline Not Good & 9.89 & 3.42 & $1.50-7.37$ \\
\hline Protective factor score & 6.77 & 0.71 & $0.55-0.92$ \\
\hline Religiosity score & 20.17 & 0.51 & $0.15-0.92$ \\
\hline \multicolumn{4}{|l|}{ Loneliness } \\
\hline Always & 6.57 & 2.23 & $1.21-4.13$ \\
\hline Sometimes & & 1 & \\
\hline \multicolumn{4}{|c|}{ Number of parents who smoke } \\
\hline None & & 1 & \\
\hline One & 13.41 & 1.80 & $1.32-2.45$ \\
\hline Both & 7.14 & 6.50 & $1.65-25.65$ \\
\hline \multicolumn{4}{|l|}{ Number of Best friend/s } \\
\hline None & & 1 & \\
\hline One & 2.54 & 3.45 & $0.75-15.81$ \\
\hline Two & 6.26 & 4.40 & $1.38-14.03$ \\
\hline \multicolumn{4}{|c|}{ Rosenberg self-esteem scale } \\
\hline Low & 2.56 & 1.26 & $0.95-1.66$ \\
\hline High & 1 & & \\
\hline
\end{tabular}

and a smaller-scaled study among adolescents in Kinta, Perak [22]. In addition, this prevalence was also higher than those reported in Thailand (8.8\%) and Philippines (11.0\%) [23]. The higher proportion of smoking among school going adolescents in Malaysia might due to the measure/s implemented to address the problem of smoking among adolescent in Malaysia are not as comprehensive and throughout as compared to those countries, On the other hand, the smoking ratio of 10:1 among male and female Malaysian adolescents was comparable with those reported in other local studies as well as several Asian countries [11, 22, 24]. However, it was not in line with those demonstrated in western countries, whereby an almost equal proportion of male and female adolescent smokers was observed [25]. These contradictory findings can be explained by the fact that smoking among females was less likely to be accepted as compared to their male counterparts, especially in the Asian society such as Malaysians. In addition, male adult smokers may also pay a significant role in influencing adolescent males to initiate and adopt smoking behaviour since the Social Learning Theory proposed that learning via observation is more effective among the same gender [26]. Also, unconscious biases and cultural scripts that daughters are in need of more 'protection' which led to more parental attention could also be the plausible reason of lower smoking prevalence among Malaysian female adolescents. In contrast, researchers stipulated that the rising prevalence of female smoking in the western regions could be partly due to the change of social norm (permissible society norm) towards smoking among females [27].

The sale of cigarettes to persons aged below 18 yearold is prohibited under the smoking control regulation in Malaysia since 2006. However, almost two-thirds of adolescent smokers in the present study, 65.4\% Form Four students (aged 16 years old) in Petaling District, Malaysia [11] and 68.3\% Malaysian adolescents [28] reported that they were able to purchase cigarettes from commercial sources. This implies that the law was not being taken seriously and/or the existing enforcement is inadequate [29-31]. This calls for stricter enforcement, especially near education facilities, as studies had showed that effective law enforcement could reduce commercial source of cigarettes [32-34] and ultimately reduce adolescent smoking [35].

This study also found that most adolescents initiated smoking during upper primary or lower secondary schooling period. This finding resonates with those reported by by Lim et al. and studies conducted in developed countries $[12,15,36,37]$. This might be because adolescents at this age feel that they are constantly at the center of attention and the people surrounding them are inspecting either their appearance or actions. This belief might drive them into conducting risk-taking actions, as such initiating smoking [38]. Nevertheless, future studies are recommended to explore the association or causal effect of adolescents emotion/feeling and smoking behaviour.

The present study demonstrated a dose-response relationship between adolescent smoking and the smoking status of one or two parent(s). The likelihood of smoking increased when both parents smoked. These findings were consistent with those reported elsewhere [14, 39-43]. According to Bandura's concept of "delayed modelling" [44], during childhood, an individual learns or remembers how to perform behaviour from seeing it modelled by their parents. Therefore, parents who smoked in front of their children would act as a role model for their children and also indirectly provide an impression that smoking is a normative behaviour among adults [45]. The mentally immature adolescents would adopt the smoking behaviour of their parents to satisfy their desire to be like an adult. 
Furthermore, parents who smoked were usually more liberal when dealing with smoking issues [46] and therefore less likely to convey the hazard of smoking to their children [47], which would ultimately lead to the thinking that smoking is acceptable and permissible by their smoking parents. In addition, smoking parents may also think that they do not have legitimate authority to advice or convince their children not to smoke because they themselves are smokers [48].

Having more best friends had been demonstrated by many studies to be a protection factor against smoking since having more friends would enable the sharing of problems, reducing stress and therefore reduce the likelihood in involving in risky health behaviors such as smoking. However, the present study demonstrated a contradictory finding. This could be partly explained by the Hemophilia Theory posited by Brickers et al. who stated that smoking adolescents tend to be friend with those who also shared similar behavior, i.e., smoking [49]. However, further study is needed to elucidate the actual reason for such association.

The present findings corroborated the well-established evidence that unsatisfactory academic achievement was a significant risk factor associated with adolescent smoking $[12,13,15,50]$. Good academic achievement might be a manifestation of cognitive gains, which may assist adolescents to understand and underscore the negative impacts of unhealthy behaviors such as smoking, which may then drive them away from the behaviour. In contrast, students who experienced academic failures may less attached to school and may befriend peers who smoked, thus increase the likelihood for them to perform similar behaviour [51, 52].

Adolescents who always felt lonely were more likely to smoke compared to those who did not. This finding was in accordance with a study by Page et al. [53] who reported that lonely boys and girls were more likely to smoke in Chile and Namibia. In addition, Stickly et al. [54] also reported that lonely boys and girls in Russia and the USA had higher odds for engaging in at least one type of risky substance-abuse behaviour. Similar finding was reported by Park [9] among adolescents in Korea. Cigarette use may be a mean to assuage the negative feelings that arose from being lonely [53]. Alternatively, loneliness may be an indication of other psychological problems, such as stress and depression [55, 56], and people usually perceived smoking can alleviate stress, depression and other psychological problems.

The present findings demonstrated that religiosity score was inversely associated with smoking and such findings were consistent with other local studies $[13,57,58]$ as well as few other studies in United State of America (USA) [59-61]. This might be explained by the Social Control Theory, which posited that the internalization of religion among adolescents could motivate them to follow the tenets stipulated in their religion. In the present study, a majority of adolescents were Muslims and since Islam does not encourage smoking (Makruh), this may explain the protective effect of high religiosity against smoking. In addition, study had also demonstrated that higher religiosity was positively associated with mental wellbeing and coping mechanisms which are related to cigarette smoking [59]. Besides, adolescents who embraced higher religiosity were more likely to befriend with peers who had similar values [62] hence encouraging and promoting positive behaviour through peer modelling and social support [63].

Respondents who scored higher on the protection score (perception towards attention, family relationships and assistance given by friends in school) were less likely to smoke. This finding was in line with the those reported by Shakib et al. [64] who revealed that a decrease in family concern was the main factor associated with smoking among adolescents in China. In addition, Wen and Shenessa [65] and Wang et al. [66] had also found that adolescents who perceived more attention from parents were less likely to smoke. As adolescents who had a good relationship with their parents tend to be more satisfied with life, more future-oriented and less stressed. Furthermore, assistance by schoolmates might enable adolescents to share their problems and reduce stress, which might help them to avoid risky health behaviour, such as smoking.

\section{Limitations}

This study was not without limitations. First, the crosssectional nature of the study only allowed determination of the association between dependent and independent variables but not causal relationship. Second, the smoking status of adolescents was self-reported without any biochemical validation such as measurement of cotinine level in urine. Third, the generalization of the findings from this study can only be applied to school-going adolescents aged 16 to 17 years but not to all school-going adolescents in Malaysia. Finally, recall bias especially on several elements such as number of cigarette smoked per day was inevitable.

\section{Conclusion}

In conclusion, this study provides evidence-based findings for the planning and implementation of targeted public health policies to combat the relatively high prevalence of adolescent smoking. Anti-smoking campaigns should concentrate or emphasize more on male adolescents, those of Malay descent, with unsatisfactory academic achievements and had smoking family members and/or peer. Parents/guardians, particularly those who smoked should also be invited to be involved in all anti-smoking activities together with their children in 
order to serve as a positive role model to discourage non-smoking adolescents from initiating this habit and for smoking adolescents to quit smoking. Last but not least, enforcement activities towards the sale of tobacco products to adolescents and smoking in public areas should be enhanced to prevent smoking initiation and to denormalize smoking as a norm in our society.

\section{Abbreviations}

COPD: Chronic obstructive pulmonary disease; GSHS: Global school-based student's health survey; IHD: Ischemic heart disease; MyaHRB: Malaysian Adolescent Health Risk Behaviour; YBRS: Youth Risk Behaviour Surveillance; YLL: Years of life lost

\section{Acknowledgements}

We would like to thank the Director-General of Health Malaysia for his permission to publish this paper. We would also like to thank those who were involved in the study and assisted in data collection and management for their support and cooperation

\section{Funding}

Self funding

\section{Availability of data and materials}

Please contact author for data requests.

\section{Authors' contributions}

LKH wrote the manuscript, LHL carried out statistical analysis, SMG and KCC design the study, KYY and SSG responsible for data collection, and coordination of the study. Jane LMY manage and clean the data. TCH and TEO were involved in interpretation and implications of the analysis. All authors contributed to developing the manuscript, and read and approved the final version.

\section{Competing interests}

The authors declared that they have no competing interest.

\section{Consent for publication}

Director General of Health, Malaysia granted the permission for publication of the manuscript.

\section{Ethics approval and consent to participate}

Ethical approval for the study was granted by Malaysia Research Ethical Committee, Ministry pf Health Malaysia. The parent/guardian given the consent for their son/daughter to participate in the study.

\section{Author details \\ ${ }^{1}$ Institute for Medical Research, Jalan Pahang, 50588 Kuala Lumpur, Malaysia. ${ }^{2}$ Melaka Manipal Medical College, Jalan Batu Hampar, Kuala Lumpur 75150, Melaka, Malaysia. Institute for Public Health, Jalan Bangsar, 50590 Kuala Lumpur, Malaysia. ${ }^{4}$ Allied Health College, Jalan Hospital, 47000 Sg. Buloh, Malaysia.}

Received: 17 February 2016 Accepted: 27 December 2016 Published online: 31 January 2017

\section{References}

1. World Health Organization. WHO report on the global tobacco epidemic, 2011. Geneva: World Health Organization; 2011. Accessed 7 Apr 2015.

2. Disease Control Division, Ministry of Health. Clinical practice guidelines on treatment of tobacco use and dependence. 2003. http://www.acadmed.org. my/view_file.cfm?fileid=89. Accessed on 26 Dec 2016.

3. Institute of Public Health. Burden of disease and injury in Malaysia. 2012.

4. Al-Junid SM. Health care costs of smoking in Malaysia. 2007.

5. Fleming R, Leventhal H, Glynn K, Ershler J. The role of cigarettes in the initiation and progression of early substance use. Addic Behav. 1989;14(3):261-72
6. Jackson C, Sweeting H, Haw S. Clustering of substance use and sexual risk behaviour in adolescence: analysis of two cohort studies. BMJ Open. 2012;2 e000661.

7. Busch V, Van Stel HF, Schrijvers AJ, de Leeuw JR. Clustering of health-related behaviors, health outcomes and demographics in Dutch adolescents: a cross-sectional study. BMC Public Health. 2013:13:1118.

8. U.S. Department of Health and Human Services. The health consequences of smoking: a report of the surgeon general. Atlanta (GA): U.S. Department of Health and Human Services, Centers for Disease Control and Prevention, National Center for Chronic Disease Prevention and Health Promotion, Office on Smoking and Health; 2004.

9. Park SH. Smoking behavior and predictors of smoking initiation in childhood and early adolescence. J Korean Acad Nurs. 2009:39(3):376e85.

10. Millar WJ, Chen J. Age of smoking initiation: implications for quitting. Health Rep. 1998;9(4):39e46

11. WHO. Global school-based student health survey, Malaysia. 2012 fact sheet. 2012. http://www.cdc.gov/gshs/countries/seasian/pdf/2012yseh_factsheet. pdf. Accessed 23 Dec 2015

12. Lim KH, Sumarni MG, Kee CC, Christopher VM, Noruiza Hana M, Lim KK, Amal NM. Prevalence and factors associated with smoking among form four students in Petaling District, Selangor, Malaysia. Trop Biomed. 2010:27(3):394-403.

13. Naing NN, Zulkifli A, Razlan M, et al. Factors related to smoking habits of male adolescents. Tob Induced Dis. 2004;2:133-40.

14. Shamsuddin K, Haris MA. Family influence on current smoking habits among secondary school children in Kota Bharu, Kelantan. Singapore Med J. 2000:41(4):167-71.

15. Lim KH, Amal NM, Hanjeet K, Mashod MY, Wan Rozita WM, Sumarni MG, Hadzrik NO. Prevalence and factors related to smoking among secondary school students in Kota Tinggi District, Johor, Malaysia. Tinggi District, Johor, Malaysia. Tinggi District, Johor, Malaysia. Trop Biomed. 2006:23(1):75-84

16. Norbanee TH, Norhayati MN, Norsa'adah B, Naing NN. Prevalence factors influencing smoking amongst Malay primary school in Tumpat, Kelantan. Southeast Asian J Trop Med Public Health. 2006;37(1):23-8.

17. Nor A, Zulkefli M, Rahmah MA, Lye MS, Md Said S, Fazilah S, Shamsul Azhar S. smoking behavior among adolescents in rural schools in Malacca, Malaysia - a case-control study. Pertanika J Sci \& Technol. 2015;23(1):13-28.

18. Saari AJ, Kentala J, Matilla KJ. Weaker self-esteem in adolescence predicts smoking. BioMed Res Int. 2015;2015:1-5.

19. Centers of Disease Control and Prevention.Global School Health Survey (GSHS) questionnaire. http//wwww.who.int/chp/gshs/GSHS_Core_modules_2013_English. pdf. Accessed on 29 Dec 2015

20. Centers of Disease control and Prevention. Youth Behavior Risk Surveillance. 2013. https://www.cdc.gov/healthyyouth/data/yrbs/pdf/2017/2017_yrbs_ national_hs_questionnaire.pdf. Accessed on 29 Dec 2015.

21. Jamil MBY. Validity and reliability study of Rosenberg self-esteem scale inSeremban school children. Malaysian J Psychiatry. 2006;15:35-8.

22. Jeganathan PD, Hairi NN, Al Sadat N, Chinna K. Smoking stage relations to peer, school and parental factors among secondary school students in Kinta, Perak. Asian Pac J Cancer Prev. 2013;14(6):3483-9.

23. Page RM, Dennis M, Lindsay GB, Merrill RM. Psychosocial distress and substance use among adolescents in four countries: Philippines, China, Chile, and Namibia. Youth Soc. 2011;43:900-30.

24. Rao S, Aslam SK, Zaheer S, Shafique K. Anti-smoking initiatives and current smoking anti-smoking initiatives and current smoking among 19,643 adolescents in south asia: findings from the global youth tobacco survey. Harm Reduc J. 2014;11:8.

25. Huisman M, Kunst AE, Mackenbach JP. Inequalities in the prevalence of smoking in the European Union. Prev Med. 2005;40:756-64.

26. Graham H. Smoking prevelance among women in the European community 1950-1990. Soc Sci Med. 1996:43:243-54.

27. Bandura A. Social learning theory. New Jersey: Prentice-Hall, Inc; 1977.

28. Sirirassamee T, Sirirassamee B, Borland R, Maizurah O. Smoking behavior among adolescents in thailand and Malaysia. Southeast Asian J Trop Med Public Health. 2011:4(2):218-24.

29. Malaysian Food Act. The control of tobacco product (amendment) regulations, 2004 Government Gazette P.U.(A) 324. 1993.

30. Zulkifli A, Rogayah I. Cigarette sales to minors in Kelantan. Med J Malaysia. 1998:53:128-30

31. Nazarzadeh M, Bidel Z, Ayubi E, Bahrami A, Jafari F, Mohammadpoorasl A, Delpisheh A, Taremian F. Smoking status in Iranian male adolescents: a cross-sectional study and a meta-analysis. Addic Behav. 2013;38(6):2214-8. 
32. US Department of health and Human Service Monitoring. The Future National Survey Result on Drug Use, 1975-2006 with the URL of : http:// monitoringthefuture.org/pubs/monographs/vol_2006.pdf. Accessed 29 Dec 2015.

33. Philippines Country Report. Department of Health with URL of http://www. doh.ph/sites.default/files/publications/2011GYTS_CountryReport.pdf. Accessed on 26 Dec 2015.

34. Widome R, Forster JL, Hannan PJ, Perry CL. Longitudinal pattern of youth access to cigarettes and smoking progression: Minnesota Adolescent Community Cohort (MACC) study (2000-2003). Prev Med. 2007:45:442-6.

35. DiFranza JR. Adolescent acquisition of cigarettes through non commercial source. J Adoles Heal. 2003;32(5):331-2.

36. Eun ES, Ji YY. Factors associated with early smoking initiation among Korean adolescents. Asian Nurs Res. 2015;9(2):115-9.

37. Goldade K, Choi K, Bernat DH, Klein EG, Okuyemi KS, Forster J. Multilevel predictors of smoking initiation among adolescents: findings from the Minnesota Adolescent Community Cohort (MACC) study. Prev Med. 2012; 54(3-4):242-6.

38. Santrock JW. Adolescence. 11th ed. Boston: McGraw-Hill; 2005.

39. Rajan KB, Leroux BG, Arthur V, Peterson Jr, Bricker JB, Andersen MR, Kealey CA, Sarason IG. Nine-year prospective association between older siblings smoking and children's daily smoking. J Adoles Healt. 2003;1:25-30.

40. Woodruff SI, Laniado-Laborín R, Candelaria Jl, Villaseñor A, Sallis JF. Parental prompts as risk factors for adolescent trial smoking: Results of a prospective cohort study. Addic Behav. 2004;9:1869-73.

41. Scalici F, Schulz JP. Influence of perceived parent and peer endorsement on adolescent smoking intentions: parents have more say, but their influence wanes as kids get older. plos one. 2014;9(7):1-7.

42. Gilman SE, Rende R, Boergers J, Abrams DB, Buka SL, Clark MA. Parental smoking and adolescent smoking initiation: an intergenerational perspective on tobacco control. Pediatrics. 2009;123(2):e274-81.

43. Blokland Exter EA, Engels RC, Hale WW, Meeus W, Willemsen MC. Lifetime parental smoking history and cessation and early adolescent smoking behavior. Prev Med. 2004;38:359-68

44. Bandura A. Self-efficacy mechanism in physiological activation and health and promoting behavior. In: Madden J, Matthysse S, Barchas J, editors. Adaptation, learning and affect. New York: Raven; 1989. p. 1169-88.

45. Bandura A. Social cognitive theory. In: Vasta R, editor. Annals of child development, Six theories of child development, vol. 6. Greenwich: JAl Press; 1989. p. 1-60.

46. Kodl MM, Mermelstein R. Beyond modeling: parenting practices, parental smoking history, and adolescent cigarette smoking. Addict Behav. 2004;29: 17-32.

47. Chassin L, Presson C, Seo DC, Sherman SJ, Macy J, Wirth RJ, Curran P. Multiple trajectories of cigarette smoking and the intergenerational transmission of smoking: a multigenerational, longitudinal study of a Midwestern community sample. Heal Psycho. 2008;27:819-28.

48. Sargent JD, Dalton M. Does parental disapproval of smoking prevent adolescents from becoming established smokers? Pediatrics. 2001;108(6): 1256-62.

49. Bricker JB, Andersen MR, Rajan KB, Sarason IG, Peterson AV. The role of schoolmates' smoking and non-smoking in adolescents' smoking transitions: a longitudinal study. Addiction. 2007;102:1665-75.

50. Morin AJ, Rodriguez D, Fallu JS, Maïano C, Janosz M. Academic achievement and smoking initiation in adolescence: a general growth mixture analysis. Addiction. 2012;107(4):819-28.

51. Dhavan P, Stigler MH, Perry CL, Arora M, Reddy KS. Is tobacco use associated with academic failure among government school students in urban India? J Sch Health. 2010;80(11):552-60.

52. Aloise-Young PA, Cruickshank C, Chavez EL. Cigarette smoking and perceived health in school dropouts: a comparison of mexican american and non-hispanic white adolescents. J PediatrPsychol. 2002;27(6):497-507.

53. Page RM. Loneliness and adolescent health behavior. Health Educ. 1990;21: 14-7.

54. Stickley A, Koyanagi A, Koposov R, Schwab-Stone M, Ruchkin V. Loneliness and health risk behaviours among Russian and U.S. adolescents: a crosssectional. BMC Public Health. 2014;14:366.

55. Heinrich LM, Gullone E. The clinical significance of loneliness: a literature review. Clin Psychol Rev. 2006;26:695-718.

56. Rotenberg KJ, McDougall P, Boulton MJ, Vaillancourt T, Fox C, Hymel S. Cross-sectional and longitudinal relations among peer-reported trustworthiness, social relationships, and psychological adjustment in children and early adolescents from the United Kingdom and Canada. J exp Child Psychol. 2004;88:46-67.

57. Fadhli Y, Zulkifli A, Razlan M. Religious perception and other associated factors of smoking among male secondary school students in Kota Baru, Kelantan. Mal J Pub Heal Med. 2005;5(2):58-63.

58. Nor Afiah MZ, Rahmah MA, Salmiah MS, Fazilah S, Shamsul Azhar S. Religiosity personality and smoking among form two students in rura schools in Malacca, Malaysia. Int Med J Malaysia. 2012;11(2):39-44.

59. Nonnemaker J, McNeely C, Blumb RW. Public and private domains of religiosity and adolescent. Soc Sci Med. 2006;62:3084-95.

60. Wallace JM, Forman T. Religion's role in promoting health and reducing risk among American youth. Health Educ Behav. 1998;25:721-41.

61. Choi WS, Ahluwalia JS, Harris KJ, Okuyemi K. Progression to established smoking: the influence of tobacco marketing. Am J Prev Med. 2002;22(4): 228-33.

62. Coleman JS. Social capital and the creation of human capital. Am J Sociol. 1998:94:595-120.

63. Smith $\mathrm{C}$. Theorizing religious effects among theorizing religious effects among theorizing religious effects among american adolescents. J Sci Study Relig. 2003;42(1):17-30.

64. Shakib S, Hong Z, Johnson CA, Chen XG, Ping S, Palmer PH. Family characteristics and smoking among urban and rural adolescents living in China. Prev Med. 2005;40(1):83-91.

65. Wan X, Sheenassa SD. Interaction between parenting and neighbourhood quality on the risk of adolerscents regular smoking. Nicotine Tobacco Res. 2012;14(3):313-22

66. Wang Y, Krishnakumar A, Narine L. Parenting practices and adolescent smoking in mainland China: the mediating effect of smoking-related cognitions. J Adolescent Health. 2014;37:915e925.

\section{Submit your next manuscript to BioMed Central and we will help you at every step:}

- We accept pre-submission inquiries

- Our selector tool helps you to find the most relevant journal

- We provide round the clock customer support

- Convenient online submission

- Thorough peer review

- Inclusion in PubMed and all major indexing services

- Maximum visibility for your research

Submit your manuscript at www.biomedcentral.com/submit
) Biomed Central 